\title{
Hubungan Status Gizi, Usia Menarche dengan Dismenorea pada Remaja Putri Di SMK K Tahun 2017
}

\author{
Nurul Husnul Lail \\ Universitas Nasional \\ J1. Sawo Manila, RT.14/RW.3, Ps. Minggu, Kota Jakarta Selatan, Daerah Khusus Ibukota Jakarta 12520 \\ Email: nurulhusnul76@gmail.com
}

\begin{abstract}
Abstrak
Berdasarkan Badan Kesehatan Dunia (WHO) angka dismenore di dunia sangat besar, rata-rata lebih dari 50\% perempuan di setiap Negara mengalami dismenore. Di Swedia sekitar 72\%. Di Amerika Serikat diperkirakan hampir $90 \%$ wanita mengalami dismenore, dan 10-15\% diantaranya mengalami dismenore berat, yang menyebabkan mereka tidak mampu melakukan kegiatan apapun. Di Indonesia sendiri kejadian dismenore cukup besar,menunjukkan penderita dismenore mencapai 60-70\% wanita di indonesia.Angka kejadian dimenore tipe primer di Indonesia adalah 54,89\%,sedangkan sisanya 45,11\% adalah tipe sekunder. Penelitian ini bertujuan untuk mengetahui Hubungan Status Gizi Dan Usia Menarche Dengan Dismenorea Pada Remaja Putri Di SMK "K". Penelitian ini menggunakan pendekatan survey analitik deskriptif dengan pendekatan Cross Sectional. Populasi dalam penelitian ini adalah seluruh siswi berjumlah 32 orang. Teknik pengambilan sampel yang digunakan adalah total sampling. Hasil penelitian menunjukkan bahwa ada hubungan antara status gizi dengan Dismenorea Pada Remaja Putri dengan nilai pvalue $=0,013<0,05$, dan ada hubungan antara usia menarche dengan dismenorea pada remaja putri dengan nilai pvalue $=0,001<0,05$. Disarankan kepada para siswi untuk senantiasa mau mengetahui apa itu dismenorea dan mengetahui faktor-faktor resiko dismenorea dalam kehidupan sehari-hari.
\end{abstract}

Kata Kunci : : Dismenorea, Status Gizi, Usia Menarche

\begin{abstract}
According to the World Health Organization (WHO) the rate of dysmenorrhea in the world is very large, on average more than 50\% of women in each country experience dysmenorrhea. In Sweden around $72 \%$. In the United States it is estimated that nearly 90\% of women experience dysmenorrhea, and 10-15\% of them experience severe dysmenorrhea, which causes them to be unable to carry out any activities. In Indonesia alone the incidence of dysmenorrhea is quite large, indicating that people with dysmenorrhea account for 60-70\% of women in Indonesia. The incidence of primary types of dimenorrhea in Indonesia is $54.89 \%$, while the remaining $45.11 \%$ are secondary types. This study aims to determine the relationship between nutritional status and age of menarche with dysmenorrhea in young women in " $K$ " vocational school. This study uses a descriptive analytical survey approach with a Cross Sectional approach. The population in this study were all 32 female students. The sampling technique used is total sampling. The results showed that there was a relationship between nutritional status and dysmenorrhea in young women with a value of $p$ value $=0.013<0.05$, and there was a relationship between age of menarche and dysmenorrhea in young women with a value of pvalue $=0.001<0.05$. It is recommended that students always want to know what dysmenorrhea is and know the risk factors for dysmenorrhea in their daily lives.
\end{abstract}

Keywords: Dysmenorrhea, Nutritional Status, Age of Menarche. 


\section{Pendahuluan}

Dismenorea adalah nyeri sewaktu haid. Dismenorhea terdiri dari gejala yang kompleks berupa kram perut bagian bawah yang menjalar ke punggung. Dismenorhea dapat diklasifikasikan menjadi dua, yaitu dismenorhea primer dan dismenorhea sekunder. ${ }^{1}$

Berdasarkan Badan Kesehatan Dunia (WHO) angka dismenore di dunia sangat besar, rata-rata lebih dari $50 \%$ perempuan di setiap Negara mengalami dismenore. Di Swedia sekitar 72\%. Di Amerika Serikat diperkirakan hampir $90 \%$ wanita mengalami dismenore, dan $10-15 \%$ diantaranya mengalami dismenore berat, yang menyebabkan mereka tidak mampu melakukan kegiatan apapun. ${ }^{2}$ Menurut Journal Pediomaternal tahun 2013, di Africa 85,4\% remaja putri mengalami dismenore primer. Sama halnya dengan hasil penelitian yang dilakukan oleh Gagua et al (2012) di Jerman, bahwa $52,07 \%$ remaja putri mengalami dismenore primer. $^{3}$

Di Malaysia,dilaporkan bahwa sebanyak $74,5 \%$ dari gadis-gadis yang telah mencapai menarche mengalami dismenore.Sedangkan di India dari 183 remaja usia 14-19 tahun ditemukan sebanyak 119 atau $65 \%$ remaja mengalami dismenore. ${ }^{4}$ Data dari Riskesdas Depkes RI tahun 2013, menunjukkan bahwa prevalensi obesitas pada kelompok umur dewasa sebesar $15.4 \%$ dan overweight sebesar $13.5 \%$. Jika prevalensi obesitas dan overweight digabungkan, maka prevalensi penduduk Indonesia yang mengalami kelebihan berat badan sebesar 28.9 \%. ${ }^{5}$ Menurut Kemenkes RI (2013) Ini adalah jumlah yang cukup besar karena lebih dari seperempat atau hampir sepertiga penduduk Indonesia pada kelompok umur dewasa mengalami kelebihan berat badan. ${ }^{6}$

Di Indonesia sendiri kejadian dismenore cukup besar,menunjukkan penderita dismenore mencapai $60-70 \%$ wanita di indonesia.Angka kejadian dimenore tipe primer di Indonesia adalah $54,89 \%$,sedangkan sisanya $45,11 \%$ adalah tipe sekunder. ${ }^{7}$ Dinas Kesehatan Provinsi Tangerang, di Puskesmas wilayah Provinsi Tangerang pada tahun 2011, total jumlah kunjungan pasien dismenore yaitu sebanyak 237 kasus, tahun 2012 meningkat sebanyak 435 kasus, dan tahun 2013 terdapat 424 kasus. $^{8}$

Faktor resiko yang menyebabkan terjadinya dismenorea diantaranya yaitu usia menarche yang cepat yaitu $<12$ tahun, riwayat ibu atau saudara kandung yang mengalami dismenorea, overweight, atupun obese.Daftary dan Patky (2012) menyatakan bahwa overweight dan obese membawa peranan sebagai faktor terjadinya dismenorea. ${ }^{9}$

Prevalensi dismenorea cukup tinggi pada remaja. Dampak yang ditimbulkan dari dismenorea adalah penurunan aktifitas seharihari sampai penggunaan terapi. Faktor risiko dismenore tidak hanya berkaitan dengan faktor fisiologis tapi juga faktor psikologi termasuk kecemasan. Data-data tersebut diatas adalah data di negara lain dan masih sangat sedikit didapatkan data mengenai gambaran, akibat yang ditimbulkan, dan faktor terkait dengan dismenore pada remaja di Indonesia. Gejalagejala dismenore adalah kram dan sakit perut bagian bawah, sakit pada punggung belakang bagian bawah, mual, diare, muntah, kelelahan, pingsan, kelemahan dan sakit kepala. Wanita yang kelebihan berat badan, merokok, dan sudah mengalami menstruasi sebelum berumur sebelas tahun berada pada risiko yang lebih tinggi mengalami dismenore. Wanita yang minum alkohol selama menstruasi mengalami nyeri haid yang berkepanjangan. ${ }^{10}$ Upaya Pemerintah Sejak tahun 2000, pemerintah Indonesia telah mengangkat KRR (Kesehatan Reproduksi Remaja) menjadi program nasional. Program KRR (Kesehatan Reproduksi Remaja) merupakan pelayanan untuk membantu remaja memiliki status kesehatan reproduksi yang baik melalui pemberian informasi, pelayan konseling, dan pendidikan keterampilan hidup. ${ }^{11}$ Berdasarkan studi pendahuluan yang dilakukan pada siswi SMK Kesehatan terhadap 32 orang,di dapatkan 10 orang $(31,3 \%)$ remaja putri yang mengalami dismenorea dan 22 orang $(68,8 \%)$ remaja putri yang tidak mengalami dismenorea.Berdasarkan latar belakang di atas, peneliti ingin melakukan penelitian tentang Hubungan Status Gizi Dan Usia Menarche Dengan Dismenorea Pada Remaja Putri Di SMK Kesehatan. 


\section{Metode}

Penelitian ini menggunakan metode analitik dengan desain cross sectional atau studi belah lintang, yaitu variabel penelitian diukur atau dikumpulkan dalam satu waktu, artinya mengadakan pengamatan hanya sekali terhadap beberapa variabel dalam waktu bersamaan yang bertujuan untuk mengetahui hubungan status gizi dan usia menarche dengan dismenorea ditinjau dari karaktreristik responden : (status gizi dan usia menarche).Alat ukur pada penelitian ini adalah kuesioner Status Gizi Dan Usia Menarche Dengan Dismenorea Pada Remaja Putri Di SMK Tangerang Tahun 2018.

\section{Hasil}

Tabel 1. Distribusi Frekuensi remaja putri yang mengalami dismenorea, Status Gizi dan usi Menarce di SMK K Tangerang Tahun 2017

\begin{tabular}{ccc}
\hline Variabel & F & \% \\
\hline $\begin{array}{c}\text { Dismenorea } \\
\text { Ya } \\
\text { Tidak } \\
\text { Status Gizi }\end{array}$ & 10 & 31,3 \\
$\begin{array}{c}\text { Normal / baik } \\
\text { Tidak Normal / tidak } \\
\text { baik }\end{array}$ & 21 & 68,8 \\
Usia Menarche & 11 & 65,6 \\
$<$ 12 Tahun & & 34,3 \\
$\geq 12$ Tahun & 9 & 28,1 \\
& 23 & 71,9 \\
\hline
\end{tabular}

Berdasarkan tabel 1 menunjukkan dari data di atas dapat di ketahui bahwa dari 32 remaja putri yang mengalami dismenorea, terdapat 10 orang $(31,3 \%)$.Sedangkan remaja putri yang tidak mengalami dismenorea sebanyak 22 orang $(68,8 \%)$. Berdasarkan tabel 1 status gizi menunjukkan dari 32 remaja putri yang mengalami status gizi tidak normal sebanyak 11 orang $(34,4 \%)$,sedangkan status gizi yang normal sebanyak 21 orang $(65,6 \%)$. Berdasarkan tabel 1 usia menarche menunjukkan dari 32 remaja putri yang mengalami usia menarche $<12$ tahun sebanyak 9 orang ( $28,1 \%$ ), sedangkan usia menarche $\geq 12$ tahun sebanyak 23 orang $(71,9 \%)$.

Berdasarkan tabel 2 dibawah diketahui bahwa remaja putri yang mengalami dismenorea berdasarkan status gizi remaja putri yang tidak normal sebanyak 7 orang $(63,6 \%)$,sedangkan status gizi remaja putri yang normal sebanyak 3 orang $(14,3 \%)$.Remaja putri yang tidak mengalami dismenorea berdasarkan status gizi remaja putri yang tidak normal sebanyak 4 orang $(36,4 \%)$,sedangkan status gizi remaja putri yang normal sebanyak 18 orang $(85,7 \%)$. Hasil uji Statistik dengan Chi-Square di peroleh $\mathrm{P}$ Value $<\alpha(\mathrm{P}$ Value $=0,013)$ berarti pada $\alpha=$ 0,05 menunjukkan bahwa Ada Hubungan Antara Status Gizi dengan Dismenorea pada Remaja Putri. Hasil analisis diperoleh nilai OR (odds ratio) sebesar $=10.500$. Hasil ini menunjukkan bahwa remaja putri dengan

Tabel 2. Hubungan Status Gizi dengan Dismenorea Pada Remaja Putri di SMK K Tangerang Tahun 2017

\begin{tabular}{|c|c|c|c|c|c|c|c|c|}
\hline \multirow{2}{*}{ Status Gizi } & \multicolumn{4}{|c|}{ Dismenorea } & \multirow{2}{*}{ Total } & \multirow{2}{*}{$\%$} & \multirow{2}{*}{ P Value } & \multirow{2}{*}{ OR } \\
\hline & Ya & $\%$ & Tidak & $\%$ & & & & \\
\hline tidak normal & 7 & 63,6 & 4 & 36,4 & 11 & 100 & \multirow{3}{*}{0,013} & \multirow{3}{*}{10.500} \\
\hline normal & 3 & 14,3 & 18 & 85,7 & 21 & 100 & & \\
\hline Total & 10 & 31,3 & 22 & 68,8 & 32 & 100 & & \\
\hline
\end{tabular}


Tabel 3. Hubungan Usia Menarche dengan Dismenorea pada remaja putri di SMK K Tangerang Tahun 2017

\begin{tabular}{|c|c|c|c|c|c|c|c|c|}
\hline \multirow{2}{*}{$\begin{array}{c}\text { Usia } \\
\text { Menarche }\end{array}$} & \multicolumn{4}{|c|}{ Dismenorea } & \multirow{2}{*}{ Total } & \multirow{2}{*}{$\%$} & \multirow{2}{*}{ P Value } & \multirow{2}{*}{ OR } \\
\hline & $\mathrm{Ya}$ & $\%$ & Tidak & $\%$ & & & & \\
\hline$<12$ tahun & 7 & 77,8 & 2 & 22,2 & 9 & 100 & & \\
\hline$\geq 12$ tahun & 3 & 13,0 & 20 & 87,0 & 23 & 100 & 0,001 & 23.333 \\
\hline Total & 10 & 31,3 & 22 & 68,8 & 32 & 100 & & \\
\hline
\end{tabular}

status gizi tidak normal $(<18,5$ dan $>25,0$ $\mathrm{kg} / \mathrm{m} 2$ ) berpeluang 10.500 kali mengalami dismenorea dibandingkan dengan remaja putri status gizi normal $(18,5-25,0 \mathrm{~kg} / \mathrm{m} 2)$

Berdasarkan tabel 3 diketahui bahwa remaja putri yang mengalami dismenorea berdasarkan usia menarche remaja putri $<12$ tahun sebanyak 7 orang $(77,8 \%)$,sedangkan usia menarche remaja putri $\geq 12$ tahun sebanyak 3 orang $(13,0 \%)$.Remaja putri yang tidak mengalami dismenorea berdasarkan usia menarche remaja putri $<12$ tahun sebanyak 2 orang $(22,2 \%)$,sedangkan usia menarche remaja putri $\geq 12$ tahun sebanyak 20 orang $(87,0 \%)$. Hasil uji Statistik dengan Chi- Square di peroleh $\mathrm{P}$ Value $<\alpha(\mathrm{P}$ Value $=0,001)$ berarti pada $\alpha=$ 0,05 menunjukkan bahwa Ada Hubungan Antara usia menarche dengan Dismenorea pada Remaja Putri. Hasil analisis diperoleh nilai OR (odds ratio $)$ sebesar $=23.333$. Hasil ini menunjukkan bahwa remaja putri dengan usia menarche < 12 tahun berpeluang 23.333 kali mengalami dismenorea dibandingkan dengan remaja putri usia menarche $\geq 12$ tahun.

\section{Pembahasan}

\section{Distribusi yang mengalami Dismenorea di} SMK K Tahun 2017

Dari hasil penelitian yang telah di lakukan menunjukkan bahwa dari sampel 32 orang remaja putri dengan kejadian dismenorea di SMK K Tangerang yaitu yang mengalami dismenorea sebanyak 10 orang remaja putri $(31,3 \%)$,dan yang tidak mengalami dismenorea sebanyak 22 Orang (68,8\%).Penelitian 91 menemukan dari 32 responden remaja putri yang mengalami dismenorea. Ada beberapa responden yang mengalami dismenorea sebanyak 10 orang dan yang tidak mengalami dismenorea 22 orang. Setelah peneliti

melakukan observasi pada saat wawancara responden yang mengalami dismenorea ,responden mengalami nyeri haid muncul sebelum keluarnya darah haid dan sebagian responden mengalami nyeri haid setelah keluarnya darah haid,siklus menstruasinya selama 27 hari dan pada saat nyeri haid responden tidak mengkonsumsi obat - obatan dan tidak pergi ke dokter, responden mengeluh pada saat mengalami nyeri haid mengatakan sedikit menganggu aktifitas belajar dan sedikit cemas, sementara yang tidak mengalami dismenorea primer responden bersikap kooperatif dan optimis pada saat proses belajar.

\section{Distribusi Usia Menarche di SMK K Tangerang Tahun 2017}

Berdasarkan data di atas di simpulkan umur menarche dari 32 remaja putri dengan usia menarche $<12$ tahun sebanyak 9 orang ( $28,1 \%$ ), sedangkan usia menarche $\geq 12$ tahun sebanyak 23 orang (71,9\%). Penelitian menemukan dari 32 responden remaja putri yang Usia menarche <12 tahun sebanyak 9 responden sedangkan $\geq 12$ tahun sebanyak 23 responden.Setelah peneliti melakukan observasi pada saat wawancara responden yang usia menarche $<12$ tahun pada saat pertama terjadinya menstruasi mengalami nyeri haid dan siklus menstruasinya selama 28 hari dan pada 
saat nyeri haid sebagian responden mengkonsumsi obat dan ada yang tidak mengkonsumsi obat ,ada yang pergi ke dokter dan ada yang tidak pergi ke dokter,dan responden mengalami pada saat pertama terjadi menstruasi responden mengatakan sangat menganggu aktifitas belajar serta tidak masuk ke sekolah dan merasa cemas,sementara yang usia menarche $\geq 12$ tahun responden mengalami sedikit merasakan nyeri haid dan bersikap kooperatif dan optimis pada saat proses belajar dan tidak pernah absen saat sekolah.

\section{Distribusi Status gizi di SMK Kesehatan Tangerang Tahun 2017}

Berdasarkan status gizi menunjukkan dari 32 remaja putri dengan status gizi tidak normal sebanyak 11 orang $(34,4 \%)$,sedangkan status gizi yang normal sebanyak 21 orang $(65,6 \%)$. Penelitian menemukan dari 32 responden remaja putri yang status gizi tidak normal sebanyak 11 responden sedangkan yang normal sebanyak 21 responden. Setelah peneliti melakukan observasi pada saat meneliti, responden yang status gizi tidak normal rata-rata IMT responden mengalami kekurangan $\mathrm{BB}$ di karenakan pola makan responden yang tidak teratur, porsi makan nya yang sangat sedikit dalam sehari makannya 2 atau 3 kali, serta responden yang tidak menyukai makan makanan tambahan seperti snack,gorengan,dan menyemil pada malam hari,sementara yang status gizi normal dari pola makanan responden yang 3 - 4 kali sehari serta menyukai makan pada malam hari.

\section{Hubungan antara Status Gizi dengan Dismenore pada remaja putri di SMK Kesehatan Tangerang Tahun 2017}

Berdasarkan hasil penelitian pada tabel 2 didapatkan Hasil uji Statistik dengan ChiSquare diperoleh P Value $<\alpha(\mathrm{P}$ Value $=0,013)$ berarti pada $\alpha=0,05$ menunjukkan bahwa Ada Hubungan Antara Status Gizi dengan Dismenorea pada Remaja Putri.Dan di ketahui bahwa remaja putri dengan ststus gizi tidak normal mempunyai peluang untuk mengalami Dismenorea 10.500 kali lebih besar di bandingkan remaja putri dengan status gizi normal. Status Gizi adalah merupakan keadaan kesehatan akibat interaksi antara makanan,tubuh manusia dan lingkungan hidup manusia.Selanjutnya,Mc,Laren menyatakan bahwa status gizi merupakan hasil keseimbangan antara zat-zat yang masuk dalam tubuh manusia dan penggunaannya. ${ }^{12}$

Gizi kurang atau terbatas selain akan memengaruhi pertumbuhan, fungsi organ tubuh, juga akan menyebabkan terganggunya fungsi reproduksi. Hal ini akan berdampak pada gangguan haid, tetapi akan membaik bila asupan nutrisinya baik,karena Status gizi merupakan salah satu faktor resiko terjadinya dismenore, status gizi yang rendah (underweight) dapat diakibatkan karena asupan makanan yang kurang, termasuk zat besi yang dapat menimbulkan anemia. Anemia merupakan salah satu faktor yang menyebabkan kurangnya daya tahan tubuh terhadap rasa nyeri sehingga saat menstruasi dapat terjadi dismenore primer, sedangkan status gizi lebih (overweight) dapat juga mengakibatkan dismenore karena terdapat jaringan lemak yang berlebihan yang dapat mengakibatkan hiperplasi pembuluh darah atau terdesaknya pembuluh darah oleh jaringan lemak pada organ reproduksi wanita, sehingga darah yang seharusnya mengalir pada proses menstruasi terganggu dan mengakibatkan nyeri pada saat menstruasi. ${ }^{13}$

Hasil penelitian sesuai dengan penelitian yang di lakukan Asih (2012) hubungan status gizi dengan kejadian dismenore dengan menggunakan uji statistik Chi-Square didapatkan hasil $p<0,05$ ( $p$ value $=0,004)$ yang berarti ada hubungan antara status gizi dengan kejadian dismenore . Selain itu, berdasarkan uji statistik diperoleh bahwa nilai $\mathrm{OR}=6,296$, ini berarti responden dengan status gizi tidak normal yaitu underweight atau overweight, memiliki risiko 6,296 kali mengalami dismenore. $^{14}$

Hasil penelitian ini juga sejalan dengan penelitian yang dilakukan oleh Nasution (2013), tentang hubungan status gizi dengan kejadian 
dismenorea pada remaja putri di SMA swasta Istiqlal Kecamatan Delitua Kabupaten Deli Serdang, didapatkan dari hasil uji Chisquare pada hubungan status gizi dengan dismenore diperoleh nilai $\mathrm{p}=0,00(\mathrm{p}<0,05)$, artinya terdapat hubungan yang signifikan antara status gizi dengan kejadian dismenorea. ${ }^{15}$

Hasil penelitian ini tidak sesuai dengan penelitian yang di lakukan Dewi (2011) hubungan status gizi dengan kejadian dismenore dengan menggunakan uji statistik Chi-Square didapatkan hasil $p<0,05$ ( $p$ value $=0,621)$ yang berarti tidak ada hubungan antara status gizi dengan kejadian dismenore. ${ }^{16}$

Berdasarkan teori dan pendapat di atas, maka dapat dikatakan bahwa status gizi bisa memiliki hubungan dengan dismenorea walaupun ada penelitian lain yang menyatakan tidak ada hubungan. Status gizi menandakan kondisi remaja putri. Apabila remaja putri mengalami status gizi kurang maka remaja putri tersebut rentan terkena dismenorea sehingga salah satu upaya untuk pencegahan dismenorea adalah dengan cara meningkatkan status gizi menjadi normal.

\section{Hubungan antara Usia Menarche dengan Dismenorea pada remaja putri di SMK Kesehatan Tangerang Tahun 2017}

Berdasarkan hasil penelitian didapatkan Hasil uji Statistik dengan Chi-Square di peroleh $\mathrm{P}$ Value $<\alpha(\mathrm{P}$ Value $=0,001)$ berarti pada $\alpha=$ 0,05 menunjukkan bahwa Ada Hubungan Antara usia menarhe dengan Kejadian Dismenorea pada Remaja Putri. Dan di ketahui bahwa remaja putri dengan usia menarche $<12$ tahun mempunyai peluang untuk terjadinya Dismenorea Primer 23.333 kali lebih besar di bandingkan remaja putri dengan usia menarche normal .

Menarche adalah periode menstruasi yang pertama terjadi pada masa pubertas seorang wanita. ${ }^{17}$ Perubahan-perubahan kadar hormon sepanjang siklus menstruasi disebabkan oleh mekanisme umpan balik antara hormon steroid dan hormon gonadotropin. Estrogen menyebabkan umpan balik negatif terhadap
Follicle Stimulating Hormone (FSH) sedangkan terhadap Luteinizing Hormone (LH), estrogen menyebabkan umpan balik negatif jika kadarnya rendah dan umpan balik positif jika kadarnya tinggi. ${ }^{1}$

Faktor resiko terjadinya dismenore salah satunya adalah pada orang yang mengalami menarche lebih awal. ${ }^{18}$ Menarche adalah haid yang pertama terjadi, yang merupakan ciri khas kedewasaan seorang wanita yang sehat dan tidak hamil. Usia menarche dipengaruhi salah satunya oleh status gizi perempuan remaja sebelumnya. ${ }^{19}$

Hasil penelitian sesuai dengan penelitian yang di lakukan oleh Listia (2015) pada mahasiswi prodi D III Kebidanan Fakultas Ilmu Kesehatan Universitas Respati Yogyakarta,berdasarkan umur menarche dengan kejadian dismenorea diperoleh kejadian dismenorea paling banyak pada mahasiswi yang menarche pada usia $<12$ tahun sebanyak 66 (77.6\%) mahasiswi, dan mahasiswi yang dismenorea pada umur $>12$ tahun sebanyak 36 (57.1\%). Mahasiswi yang tidak mengalami dismenorea pada umur < 12 tahun sebanyak 19 (22.4\%), dan yang tidak mengalami dismenorea pada umur $>12$ tahun sebanyak 27 (42.9\%). Berdasarkan hasil uji statistik diperoleh $\mathrm{p}=$ 0.013 yang artinya terdapat hubungan antara mahasiswi yang mengalami menarche pada usia $<12$ tahun dengan kejadian dismenorea pada mahasiswi Prodi D III Kebidanan Fikes UNRIYO Tahun 2015. Nilai OR= $2.605(95 \%$ CI 1.276-5.319) yang artinya mahasiswi yang mengalami menarche pada usia $<12$ tahun mempunyai peluang 2.6 kali mengalami

Hasil penelitian ini juga sejalan dengan penelitian yang dilakukan oleh Misaroh (2009) yang menyatakan bahwa usia ideal seorang wanita mengalami menarche yaitu pada usia antara 12-14 tahun. Seseorang yang mengalami menarche $<12$ tahun memiliki kemungkinan 1,6 kali lebih besar mengalami dismenore dibandingkan umur 12-14 tahun dimana umur < 12 tahun merupakan umur beresiko remaja perempuan mengalami menstruasi pertama, hasil 
uji statistik dengan menggunkan uji chi square diperoleh nilai $\mathrm{p}$ value $=0,037$ yang berarti terdapat hubungan yang bermakna antara usia manarche dengan kejadian dismenore.Rasio prevalens kejadian dismenore pada kelompok umur menarche $<12$ tahun dengan kelompok umur menarche 12 -14 tahun adalah 1,568 $(0,598-0,716) .^{21}$

Hasil penelitian ini juga tidak sejalan dengan penelitian yang dilakukan oleh Dinengsih (2011), tentang hubungan usia menarche dengan kejadian dismenorea pada remaja putri di SMK Lingau Kecamatan Pangkalan Balai Kabupaten Banyuasin, didapatkan dari hasil uji Chisquare pada hubungan usia menarche dengan dismenore primer diperoleh nilai $\mathrm{p}=0,659(\mathrm{p}<0,05)$, artinya tidak ada hubungan yang signifikan antara usia menarche dengan dismenorea. ${ }^{22}$

Berdasarkan data di atas dapat di simpulkan bahwa antara usia menarche dengan dismenorea dengan hasil $\mathrm{P}$ Value $<\alpha(\mathrm{P}$ Value $=$ 0,001), bahwa ada hubungan Usia menarche dengan dismenorea.

\section{Kesimpulan}

1. Distribusi frekuensi remaja putri yang mengalami dismenorea. Di ketahui bahwa dari 32 remaja putri yang tidak mengalami dismenorea sebanyak 22 orang $(68,8 \%)$, status gizi yang normal $(18,5-25,0 \mathrm{~kg} / \mathrm{m} 2)$ sebanyak 21 orang $(65,6 \%)$, usia menarche $\geq 12$ tahun sebanyak 23 orang $(71,9 \%)$

2. Terdapat hubungan antara status gizi dengan dismenorea . Hasil uji Statistik dengan $\mathrm{P}$ Value $<\alpha(\mathrm{P}$ Value $=0,013)$ dan nilai $\mathrm{OR}=10.500$, dan usia menarche $(\mathrm{P}$ Value $=0,001)$ dan nilai $\mathrm{OR}=23.333$.

3. Dari penelitian ini variabel yang mempunyai peluang resiko terbesar yaitu usia menarche dengan $\mathrm{OR}=23.333$.

\section{Saran}

Setelah dilakukan penelitian, peneliti berharap pada pihak sekolah menyediakan pelayanan kesehatan dan menambah program pendidikan kesehatan serta disosialisasikan seperti penyuluhan cara mengetahui faktorfaktor resiko usia menarche dengan dismenorea dan serta berkewajiban menyampaikan informasi yang diperlukan oleh siswi pada remaja putri.

\section{Daftar Pustaka}

1. Wiknjosastro S. Ilmu Kebidanan. Indonesia: Balai Pustaka; 2012.

2. Jurnal Occupation And Environmental Medicine; 2013.

3. Gagua et al. Dysmenorrhea: Prevalence 2012.

4. Kumbhar et al Kesehatan Ibu dan Anak. Jakarta: JICA (Japan International Coorporation Agency) ; 2012.

5. Depkes RI, Profil Kesehatan Indonesia. Jakarta: 2013.

6. Kemenkes RI, Kesehatan Ibu dan Anak. Jakarta:2013

7. Puspitasari dan Novia. .Angka kejadian Dismenorea di Indonesia. 4 juni 2018

8. Dinkes Provinsi Tangerang RI. Profil Kesehatan; 2013.

9. Datta, M., Randall, L., Holmes, N., dan Karunaharan, N., Rujukan Cepat Obstetri \& Ginekologi. Penerjemah : Toni Priliono. Jakarta : Penerbit Buku Kedokteran EGC; 2009.

10. Calis. Prevalensi Dismenorea Cukup Tinggi Pada Remaja. Indonesa: Salemba Medika; 2012.

11. Kumalasari. Upaya Pemerintah Indonesia Telah Mengangkat KRR. Jakarta: Salemba Medik; 2012.

12. Irianto K. Kesehatan Reproduksi (Reproductive healt) Teori dan Praktikum. Bandung : Alfabeta; 2015.

13. Kusmiran E. Kesehatan Reproduksi Remaja dan Wanita. Jakarta: Salemba Medika; 2011.

14. Asih A.S. Analisis Kejadian Dismenore Primer Pada Remaja Putri Kelas XI SMK YAPSIPA Kota Tasikmalaya. Skripsi. Universitas Sam Ratulangi; 2012.

15. Nasution. Hubungan status gizi dengan kejadian dismenorea pada remaja putri di 
16. SMA swasta Istiqlal Kecamatan Delitua Kabupaten Deli Serdang; 2013.

17. Dewi. Hubungan status gizi dengan kejadian dismenore; 2011.

18. Proverawati dan Misaroh Faktor Risiko Dismenore Primer Pada Siswi Sekolah Menengah Pertama (Smp X) Kecamatan Natar Kabupaten Lampung Selatan. eJournal. Stikes Aisyah Pringsewu; 2009.

19. Smeltzer SC. dan Bare BG. Buku Ajar Keperawatan MedikalBedah Brunner dan Suddarth(Ed.8, Vol. 1,2), Alih bahasa oleh AgungWaluyo (dkk). Jakarta: EGC; 2002.

20. Nurillah. Angka Kejadian Dymenore Di Indonesia; 2012.

21. Listia. Gambaran Drajat Disminre dan upaya Penanganannya Pada Siswi Sekolah Menengah Kejuruan Arjuna Depok . [Skripsi]. Jakarta; 2015.

22. Misaroh. Faktor Risiko Dismenore Primer Pada Siswi Sekolah Menengah Kejuruan (Smk X) Kecamatan Lor Kabupaten Gunung Kidul ; 2009.

23. Dinengsih . Faktor - faktor yang berhubungan dengan kejadian Dismenore pada Mahasiswi Prodi DIII Kebidanan. Jakart; 2011. 